\title{
TOMBAMENTO PARTICIPATIVO EM MARTINÓPOLIS - SP
}

Lucas Loveira, Fabrícia Dias da Cunha de Moraes Fernandes Borges.

Universidade do Oeste Paulista - UNOESTE, Faculdade de Engenharias e Arquitetura e Urbanismo, Presidente Prudente, SP. E-mail: luc.loveira7@gmail.com.

\section{RESUMO}

O presente trabalho tem como função discorrer sobre as políticas públicas à cerca da preservação do patrimônio histórico juntamente com a sociedade local, sendo o objeto deste estudo a cidade de Martinópolis, SP. Desta forma, o objetivo geral desta pesquisa é compreender qual o entendimento e relevância dada pela população de Martinópolis sobre patrimônio arquitetônico, ou seja, sobre a importância de preservação de edificação na respectiva cidade, seja por motivos históricos, de memória ou estilísticos. A metodologia aplicada foi primeiramente um estudo bibliográfico sobre as noções de patrimônio histórico e formação da cidade de Martinópolis - SP, e posteriormente foi realizada uma pesquisa online com os habitantes da cidade. Como resultado, conclui-se que a edificação que os moradores da cidade consideram mais relevante para um futuro tombamento por ter função histórica e de preservação da memória da cidade é o Casarão dos Martins, edificação que pertenceu ao fundador do município.

Palavras-chave: Patrimônio Histórico, tombamento, Martinópolis, identidade, memória.

\section{PARTICIPATORY REGISTER IN MARTINÓPOLIS - SP}

\begin{abstract}
This work is to discuss role of public policy at about the preservation of historical heritage along with the local society, and the object of this study the city of Martinópolis, SP. Thus, the objective of this research is to understand what the understanding and importance given by the people of Martinópolis on architectural heritage, or on the importance of building preservation in their city, either for historical reasons, memory or stylistic. The methodology was first a bibliographic study of the historical heritage of ideas and formation of the city of Martinópolis - SP, and was subsequently conducted an online survey of the city's inhabitants. As a result, it is concluded that the building that the city's residents consider most relevant to a future tipping to have historic preservation and function of the city's memory is the Manson of Martins, building that belonged to the founder of the city.
\end{abstract}

Keywords: Historic Heritage, register, Martinópolis, identity, memory. 


\section{INTRODUÇÃO}

A preservação do patrimônio histórico é um tema que está muito presente na sociedade contemporânea, pois a agilidade no processo de crescimento das cidades acaba acarretando em uma perda do sentimento de pertencimento com os edifícios históricos, e por sua vez a perda da memória e identidade da sociedade atual. A criação de iniciativas que resgatem as nossas origens e preservem o nosso passado histórico são muito importantes para não deixar a nossa história desaparecer, e isso só acontece com o esforço do coletivo, sendo ele caracterizado pela população orientada pelo poder público (SOMEKH, 2014).

Lemos (2010) diz que o patrimônio cultural é muito diversificado e sofreu ao longo do tempo inúmeras alterações, pois nunca houve preocupação em se preservar algo pelo seu valor cultural, mas sim pelo seu valor monetário. A questão de preservação para conservação da memória é algo recente, difundido na segunda metade do século XIX.

Carlos; Souza e Sposito (2013), depois de um amplo período de tempo onde só se valorizava o que era novo, atualmente o dia a dia do brasileiro tem sido dominado por discursos que pregam a restauração e a preservação do que sobrou do nosso passado. Essa necessidade vem atrelada com a vontade de se preservar a "memoria urbana".

Segundo Somekh (2014), essa velocidade com que a cidade se transforma é consolidada em uma série de desafios, sendo eles: a inevitabilidade de se conciliar as novas necessidades de sua população com a ocupação territorial, como por exemplo, soluções na área da habitação, localização de equipamentos públicos e mobilidade, etc.

A única forma de se adaptar a essas rápidas transformações a criação de um novo planejamento urbano, mais flexível, que agrega a sociedade na formatação de suas ações. A importância do patrimônio histórico deve estar inserida no planejamento da cidade, para assim não ficar perdida em uma guerra de interesses que só visam à questão econômica que esses patrimônios podem estar ligados (SOMEKH,2014).

Com todas essas mudanças, a identidade da sociedade atual também está diferente. Manuel Castells (2014, p. 210) observa que:

A identidade está se tornando a principal e, às vezes, única fonte de significado em um período histórico caracterizado pela ampla desestruturação das organizações, desligitimação das instituições, enfraquecimento de importantes movimentos sociais e expressões culturais efêmeras.

O reconhecimento do patrimônio histórico constitui-se então de uma ferramenta de suma importância na formulação da identidade coletiva, e quando este patrimônio é escolhido através da opinião popular ele acaba agregando legitimidade. Somekh (2014), ao discutir a suma importância da vontade popular dentro das escolhas patrimoniais, diz que a legitimidade da vontade popular é a única forma de enfrentar as dinâmicas do mercado, orientando essa força popular a conservar os valores simbólicos que conservam a história da cidade.

Posto isto, a importância deste projeto se dá através da escolha de um patrimônio histórico na cidade de Martinópolis- SP através da vontade popular, conciliando assim a sua importância histórica com a legitimidade da população. A cidade possui alguns edifícios significativos, porém os dois mais importantes em questões históricas e para a realização deste trabalho são o Casarão dos Martins (Figura 1) e o Edifício da Sanbra (Figura 2). 


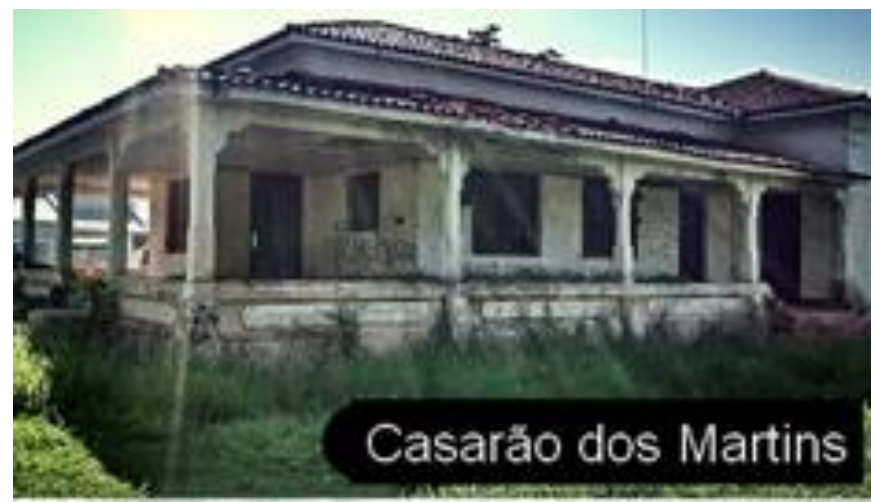

Figura 01. Casarão dos Martins

Fonte: Acervo do autor, 2016.

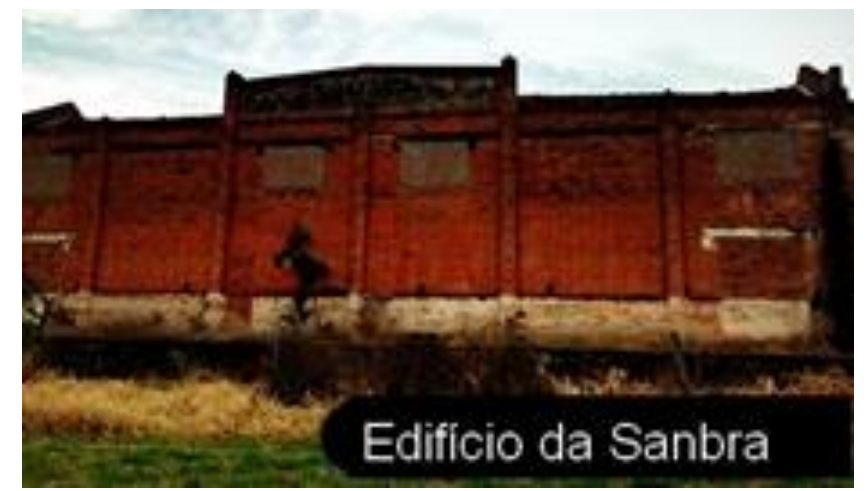

Figura 02. Edifício da Sanbra

Fonte: Acervo do autor, 2016.

Este tipo de proteção patrimonial denominado tombamento participativo visa aproximar a população de seu passado histórico, traçando relações com a memória coletiva e identidade de uma cidade, salientando a importância de que é preciso conhecer as suas próprias raízes para poder se localizar na sociedade atual.

\section{METODOLOGIA}

O presente estudo foi desenvolvido a partir de levantamento bibliográfico de diversos autores que tenham publicado suas teorias no campo da preservação e importância do patrimônio histórico. Após essa busca por fundamentação realizou-se a pesquisa em formato online com os moradores da cidade de Martinópolis.

Importante destacar na metodologia que foram aplicados questionários de opinião sobre as edificações da cidade. Por meio de consulta ao CEP, destaca-se que houve mudanças metodológicas sobre pesquisas de opinião nas áreas de ciências sociais aplicadas, e não é mais necessária a aprovação de Comitê de Ética em pesquisa para tal.

\section{RESULTADOS}

A pesquisa realizada foi feita no formato online, compartilhada através das redes sociais. Ela conta com seis questões de múltipla escolha, onde a sociedade local poderia escolher apenas uma alternativa. O questionário ficou online disponível para ser respondido no período compreendido entre 27/04/2016 até o dia 28/05/2016 e teve um total de 135 participações. A primeira questão teve como objetivo descobrir a idade das pessoas que responderam o questionário. De acordo com o gráfico abaixo, 40,7 \% das pessoas que responderam à pesquisa possuíam idade entre 18 a 28 anos, 27,4 \% possuíam idade entre 29 e 39 anos, 14,8 \% possuíam 
idade entre 40 e 50 anos, $11,1 \%$ possuíam idade entre 50 e 60 anos e 5,9 \% estavam na faixa etária de mais de 60 anos.

\section{1 - Qual a sua idade? (135 respostas)}

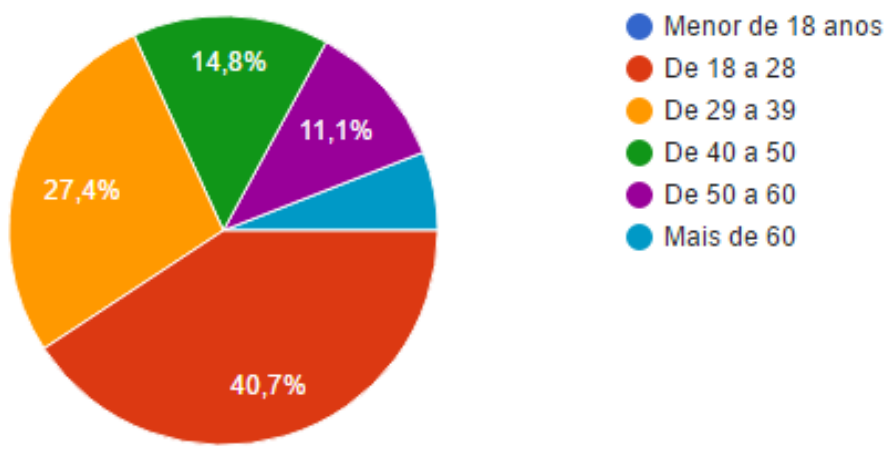

Figura 03. Gráfico sobre a idade das pessoas que responderam à pesquisa Fonte: Acervo do autor, 2016.

A segunda questão objetivava diagnosticar qual o grau de formação das pessoas que responderam à pesquisa. De acordo com os resultados observa-se que $43 \%$ das pessoas possuíam graduação completa, 31,9\% possuíam graduação incompleta, 19,3\% possuíam ensino médio completo, 3\% possuíam ensino fundamental completo, 2,2 \% possuíam ensino fundamental incompleto e $0,7 \%$ possuíam ensino médio incompleto.

\section{2 - Qual o seu grau de formação? (135 respostas)}

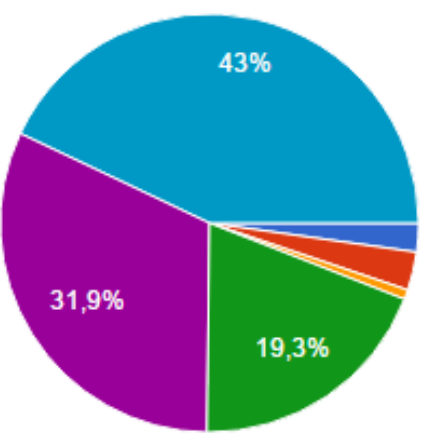

Ensino fundamenta

incompleto

Ensino fundamental completo

Ensino médio incompleto

- Ensino médio completo

- Graduação incompleta

- Graduação completa

Figura 04. Gráfico sobre o nível de escolaridade das pessoas que responderam à pesquisa Fonte: Acervo do autor, 216.

O objetivo da terceira questão foi descobrir se a população da cidade de Martinópolis considera importante a conservação dos edifícios históricos. Nos resultados foi identificado que $95,6 \%$ das pessoas que responderam à pesquisa consideram importante a conservação de edifícios antigos e 4,4 \% não consideram esta ação importante. 


\section{3 - Você considera importante a conservação de edifícios antigos?}

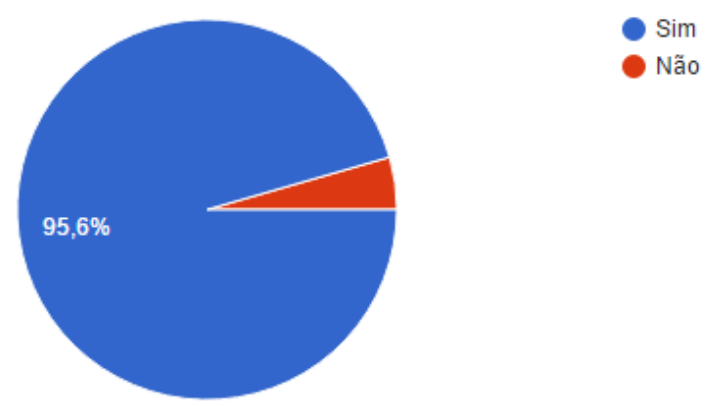

Figura 05. Gráfico sobre a importância da conservação de edifícios antigos de acordo com a população de Martinópolis

Fonte: Acervo do autor, 2016.

A quarta pergunta objetivava constatar, na opinião dos moradores da cidade de Martinópolis, qual edificação mereceria ser restaurada e preservada por ser parte integral da memória e identidade da cidade. Dentre as respostas, os edifícios mais citados foram o Casarão dos Martins, o Edifício da Sanbra e a Estação Ferroviária, porém este último foi menos citado em comparação com os outros dois edifícios. Esta questão por ser dissertativa não possui um gráfico.

A quinta questão tinha como objetivo identificar qual edificação, entre o Casarão dos Martins e o Edifício da Sanbra, os moradores locais consideravam possuir mais importância para a história da cidade de Martinópolis. De acordo com o resultado, 83, 7\% consideram o Casarão dos Martins como sendo a edificação mais importante para a história da cidade e 16,3\% consideram o Edifício da Sanbra como sendo a edificação mais importante para a história da cidade.

\section{5 - Dentre estas duas edificações, qual você considera ser a mais importante para a história da cidade? \\ (135 respostas)}

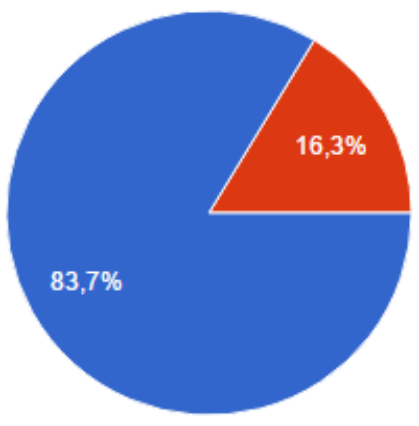

Casarão dos Martins

Edificio da Sanbra

Figura 06. Gráfico sobre a edificação com maior importância para a história da cidade de Martinópolis

Fonte: Acervo do autor, 2016.

A sexta e última pergunta do questionário objetivava diagnosticar qual a função, de acordo com os moradores locais, o edifício escolhido deveria receber depois de restaurado. De acordo com as respostas, 48,1\% escolheram a função cultural, 31,1\% escolheram a função de museu, 10,4 \% escolheram a função de lazer, 6,7\% escolheram a função de gastronomia, 1,5\% escolheram a 
opção esportiva e 2,2\% escolheram que a edificação deveria receber uma outra função além destas citadas.

\section{6 - Qual função esta edificação deveria receber para melhor atender os cidadãos da cidade? (135 respostas)}
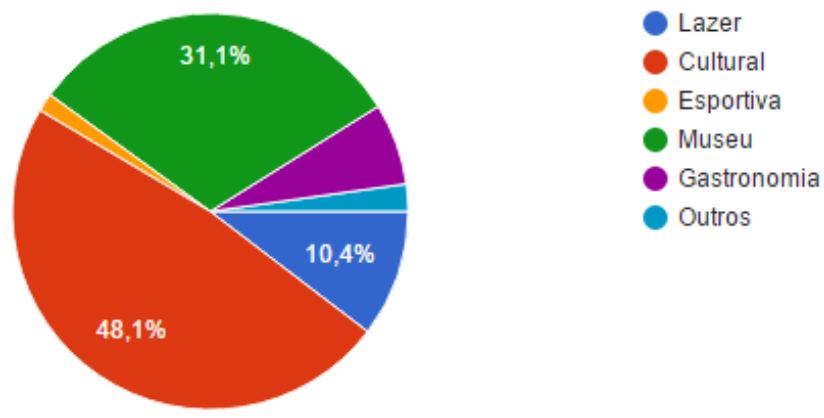

Figura 07. Gráfico sobre a futura função do edifício histórico escolhido Fonte: Acervo do autor, 2016.

\section{DISCUSSÃO}

Analisando os resultados obtidos nota-se a real importância deste trabalho. De acordo com Jacobs (2014), talvez fosse impossível para uma cidade ser considerada viva se não fosse pela importância de seus edifícios históricos. Se uma cidade possui apenas edifícios novos, só quem poderá arcar com os custos destes serão as classes mais ricas, causando assim uma das características da segregação.

Um novo planejamento urbano deve ser criado, extraindo toda a rigidez do antigo, dando liberdade para a população participar da escolha desses novos monumentos. Para que o patrimônio não seja vítima nas mãos do poder econômico ele deve ser acoplado no planejamento da cidade. O momento histórico em que estamos inseridos é caracterizado pelo grande anseio das pessoas em se identificarem com algo, terem o sentimento de pertencimento, e quando um bem é denominado patrimônio histórico com o auxílio da população, não apenas por arquitetos e estudiosos, esse patrimônio ganha autenticidade, resistindo assim pressão do mercado imobiliário (SOMEKH,2014).

De acordo com Somekh (2014), um patrimônio histórico só é valorizado quando a comunidade que convive com este tem a consciência de seu valor enquanto instrumento que auxilia na preservação de sua história e na construção de sua identidade. Sobre a democratização do patrimônio, Somekh $(2014$, p.46) afirma que "Democratizar o patrimônio não é só garantir a participação, mas garantir que as camadas menos favorecidas da população possam usufruir de seus bens históricos e se beneficiar de sua valorização".

\section{CONCLUSÃO}

Conclui-se desta forma que o tombamento participativo de uma edificação arquitetônica histórica é constituído como a melhor forma de se proteger um bem, pois desta forma agrega-se o valor da legitimidade através da vontade popular. No estudo de caso da cidade de Martinópolis, a população reconhece a importância do Casarão dos Martins como propagador da memória local e agente direto da preservação da identidade da cidade. Para que bem seja preservado ele deve receber um novo uso, e de acordo com a vontade popular o Casarão dos Martins deveria receber uma intervenção arquitetônica transformando o edifício em um centro cultural. Acredita-se também que o auxílio da população local na hora de escolher a edificação histórica que receberá 
uma intervenção e sua respectiva função faria com que este edifício fosse muito mais respeitado e protegido pela comunidade em comparação com algo imposto sem que antes fosse ouvida as opiniões dos moradores locais que possuem contato direto com o patrimônio em questão.

\section{REFERÊNCIAS}

CARLOS, A; SOUZA, M; SPOSITO, M. A produção do espaço urbano: Agentes e processos, escalas e desafios. São Paulo: Editora Contexto, 2013.

CASTELLS, M. A sociedade em rede. 12. ed. São Paulo: Paz e Terra, 2010.

JACOBS,J. Morte e vida das grandes cidades. 3. ed. São Paulo: Martins Fontes, 2014.

LEMOS, C. O que é patrimônio histórico. 2. ed. São Paulo: Brasiliense, 2010.

SOMEKH, N. Preservando o patrimônio histórico: um manual para gestores municipais. São Paulo: CAU/SP, 2014. 